\title{
TOMÉ DE SOUSA
}

Em 1534 o Rei D. João III visando acelerar a colonização do Brasil, criou as Capitanias Hereditárias, distribuídas a nobres e grandes burgueses.

Como o resultado fosse muito aquém do esperado, o Rei, em 1547, criou o Governo Geral com a finalidade de coordenar a ação dos governadores das capitanias.

O primeiro governador geral do Brasil foi o fidalgo Tomé de Sousa, cujo mandato se estendeu de 1549 até 1554 .

Dinâmico e enérgico, instalou-se na Bahia, fundando a cidade de S. Salvador, capital do Brasil até 1763. Percorreu a costa brasileira fundando fortes, visando combater a ação dos piratas franceses. Melhorou o sistema defensivo das cidades existentes. Lutou contra os índios, especialmente os tupinambás e tamoios. Apoiou a ação dos padres jesuítas, aqui chegados com ele, na catequização dos índios.

As múltiplas iniciativas de Tomé de Sousa fizeram com que junto com Mem de Sá, fosse colocado entre os melhores governadores do Brasil no século XVI.

Suas cartas relatórios, aqui transcritas, são importantes documentos para visualizarmos a ação portuguesa nos primeiros tempos da colonização do Brasil.

Harry Rodrigues Bellomo.

Estudos Ibero-Americanos. PUCRS, v.XXII, n.1, p. 191, junho, 1996 


\section{CARTA DE TOMÉ DE SOUSA 1 de junho de 1553}

1-Senhor-Eu cheguei a esta cidade do Salvador, de correr a costa, como tinha escrito a V.A. no primeiro de maio deste presente ano, e achei aqui Manuel da Fonseca, em uma naveta em que trouxera fazenda e dinheiro para esta cidade, e chegou aqui bem e a bom recado, como largamente por ele tenho escrito a V.A.; porque o despedi logo a ir tomar carga a Pernambuco, por me assim parecer bem e proveito de vossa fazenda, e eu fiquei aqui carregando, a armada em que fui, que é uma nau e duas caravelas, de madeira, para colocação e reparos de bombardas, e para outras cousas, como tenho, por aviso dos armazéns do Reino; e pareceu-me que neste tempo é tardança viesse a nau de que V.A. me escreve que me faz mercê de me mandar ir nela; e por me parecer que tardava, e que estando a armada aqui, corria risco por não ter com que consertar, nem me veio do reino, e que também chegaria a essa costa no inverno, que é grande trabalho para os navios; me pareceu bom conselho e proveito de vossa fazenda mandar Pero de Góis nestes navios, com a dita madeira; e a nau, quando vier, far-se-á o que V.A. mandar e parecer bem, ao tempo que chegarem, e nesta parte me parecer que está tudo assim bem ordenado.

2-Eu corri esta costa toda, e me pareceu que nisso fiz muito serviço a V.A. e bem à terra; ao menos fiz tudo o que pude e entendi, e gastei tudo o que tinha, e não falo no gastar para pedir algum alvitre a V.A. para minhas dívidas, se não para que V.A. saiba que o que me deu, folgo de o despender em seu serviço; e, verdadeiramente, que se ousara de fazer novidade, que me metera em uma caravela, a ir dar conta a V.A. de muitas

Estudos Ibero-Americanos. PUCRS, v.XXII, n.1, p. 193-198, junho, 1996 
cousas que se não podem escrever, e vai muito nelas em as dizer e lembrar a V.A., para o bem destas partes e, pois, já isto não pode ser, direi as que me parecerem mais necessárias, por o mais breve modo que eu puder, e o mais remeto a Pero de Góis que, além de saber desta terra mais que outrem, passou e viu tudo comigo.

3 - Todas as vilas e povoaçōes de engenhos desta costa, fiz cercar de taipa, com os seus baluartes, e as que estavam arredadas do mar, fiz chegar ao mar, e lhes dei toda a artilharia que me pareceu necessária, a qual está entregue aos vossos almoxarifes, porque os Capitães não querem ter, a que são obrigados a ter, nem têm fazendas por onde os obrigue a isso; ordene V.A. nisto o que lhe parecer seu serviço; e mandei em todas as vilas fazer casas de audiência e de prisão, e endireitar algumas ruas, o que tudo se fez sem opressão do povo e com folgarem muito de o fazer, que disto são grande parteira.

4 - Como disse a V.A. não farei senão as lembranças muito necessárias, sem as quais esta terra se não poderá sustentar, senão, se um homem pode viver sem cabeça. V.A. deve mandar que os Capitães próprios residam em suas Capitanias, e quando isto, não, por alguns justos respeitos, ponham pessoas de que V.A. seja contente, porque os que agora servem de Capitães, não os conhece a mãe que os pariu; e eu agora tirei um da Capitania dos Ilhéus, que é a melhor cousa desta costa para fazendas, e que mais agora rende para V.A., por ser cristão novo e acusado pela Santa Inquisição, e não ser para o tal cargo, em modo algum; o qual mandou o filho de Jorge de Figueiredo, que Deus haja, e provei de Capitão um homem honrado e abastado, e de boa casta, que vive na dita Capitania, e que sirva enquanto V.A. não prover, ou, o Capitão da terra, é João Gonçalves Dormundo, que é fidalgo e de cota darmas por uma Provisão de V.A.

5 - A esta cidade do Salvador deve V.A. de prover de um Capitão honrado e abastado, porque a qualidade dela o demanda assim, e o Governador Geral não deve ter lugar certo, se não residir onde lhe parecer que há mais necessidade dele.

6 - Que a justiça de V.A. entre em Pernambuco e em todas as Capitanias desta costa; e doutra maneira não se deve de tratar da Fazenda que V.A. tiver nas ditas Capitanias, nem menos da justiça que se faz.

7 - O Espírito Santo é a melhor Capitania e mais abastada que há nesta costa, mas está tão perdida como o Capitão dela que é Vasco 
Fernandes Coutinho. Eu o provi o melhor que pude, mas V.A. deve mandar Capitão, ou Vasco Fernandes que se venha para ela, e isto com brevidade.

8 - Por muitas vezes tenho escrito a V.A., que mande a estas partes até dez criados seus, e que sejam homens que tenham alguma obrigação e honra, para servirem nas Capitanias de Oficiais de sua Fazenda e de Capitães e doutras cousas, quando cumprir. Eu entrei no Rio de Janeiro, que está nesta costa, na Capitania de Martim Afonso, 50 léguas de São Vicente e 50 do Espírito Santo; mando o debuxo dela a V.A.; mas, tudo é graça o que se dela pode dizer, senão que pinte quem quiser, como deseje um Rio, isso tem este de Janeiro. Parece-me que V.A. deve mandar fazer ali uma povoação honrada e boa, porque já nesta costa não há rio em que entrem franceses, se não neste, e tiram dele muita pimenta, e fui sabedor que um ano tiraram 50 pipas, e tirarão quanta quiserem pagar os matos; andam da qualidade deste de cá, de que V.A. deve de ter informação, e escusar-se-ia com esta povoação armada nesta costa, e não ponha V.A. isto em traspaço, porque, além de ser necessário para o que digo, devia V.A. ali ter outro Ouvidor Geral, porque está em passagem para toda a costa dali e desta Cidade ser provida com Justiça e com brevidade, por respeito das monções; e se eu não fiz fortaleza este ano no dito Rio, como me V.A. escrevia, foi porque o não pude fazer, por ter pouca gente, e não me parecer siso desarme por tantas partes, e acerca deste caso, e de outra baía que se chama Angra dos Reis, e dará a V.A. larga informação Pero de Góis.

9 - São Vicente, Capitania de Martim Afonso, é uma terra muito honrada e de grandes águas e serras e campos. Está a Vila de São Vicente situada em uma ilha de três léguas de comprido e uma de largo, na qual ilha se fez outra vila que se chama Santos, a qual se fez, porque a de São Vicente não tinha tão bom porto, e a de Santos que está uma légua da de São Vicente tem o melhor porto que se pode ver; e todas as naus do mundo poderão estar nele com os proizes dentro em terra. Esta ilha me parece pequena para duas vilas; parecia-me bem ser uma só, e toda a ilha ser temo dela verdade, é que a Vila de São Vicente diz que foi a primeira que se fez nesta costa, e diz verdade, e tem uma igreja muito honrada, e honradas casas de pedra e cal, com um colégio dos irmãos de Jesus. Santos precedeu-a em porto e em sítio, que são duas grandes qualidades, e nela estão já a Alfândega de V.A. Ordenará V.A. nisto o que lhe parecer 
bem, que eu houve medo de desfazer uma vila a Martim Afonso, ainda que lhe acrescentasse três. S. a Bertioga que me V.A. mandou fazer, que está cinco léguas de São Vicente, na boca do rio por onde os índios lhe faziam muito mal; eu a tinha já mandado fazer da maneira que tinha escrito a V.A. A ordenei e acrescentei doutra maneira, que pareceu a todos bem, segundo V.A. verá por este debuxo, e ordenei outra vila no começo do campo desta Vila de São Vicente, de moradores que estavam espalhados por ele, e os fiz cercar e ajuntar, para se poderem aproveitar todas as povoações deste campo, e se chama Vila de Santo André, porque onde a situei estava uma ermid deste Apóstolo, e fiz Capitão dela a João Ramalho, natural do termo de Coimbra, que Martim Afonso já achou nesta terra quando cá veio. Tem tantos filhos, netos, bisnetos e descendentes dele, q. não ouso de dizer a V.A. Não tem cá na cabeça, nem no rosto, e anda nove léguas a pé, antes de jantar; e ordenei outra vila na borda deste campo, ao longo do mar: que se chama a Conceição, de outros moradores que estavam derramados por o dito campo, e os ajuntei e fiz cercar e viver em ordem; e além destas duas povoações serem mui necessárias para o bem comum desta Capitania, folguei de o fazer, por o que direi em outro item, abaixo desta. Estas duas Vilas de São Vicente e Santos, não estão cercadas, e as casas de maneira espalhadas, que não podem cercar senão com muito trabalho e perda dos moradores, porque tem as casas de pedra e cal, e grandes quintais, e tudo feito em desordem, por onde lhes não vejo outra melhor telha que, em cada uma delas, que fazer-se, no melhor sítio que puder e mais convinhável para sua defensão, cada uma, seu castelo, e, desta maneira, ficarão bem, segundo a qualidade da terra, e deve-se logo prover nisto quem, com razão, o deve fazer, porque doutra maneira estão mal.

10 - De Castela partiu uma armada com 300 pessoas, pouco mais ou, menos, para o rio da Prata, a qual, parte dela, na Ilha do Príncipe, na costa da Guiné, e parte na costa entre o Rio da Prata e São Vicente, 60 léguas dele, onde se chama o rio dos Patos, se perdeu quase toda, e se salvaram somente 60 pessoas, quase a metade mulheres, onde entrava também a mulher do Governador, que também faleceu, que se chamava Fernando Saraiva, e suas filhas e parentes, em que eram nove ou dez mulheres fidalgas, afora outras. Os índios, como viram que era gente parecida conosco e dizerem-lhe eles que eram irmãos nossos, não lhes fizeram mal algum, antes muito agasalho. Como se viam assim perdidos, 
veio um Capitão daquela companha que se chamava João do Solazar, que foi criado do duque d'Aveiro, a quem fez deitar o hábito de Santiago; em chegando este homem a São Vicente cheguei eu, e me pediu que mandasse buscar aqueles homens e mulheres que estavam ali perdidos. Pareceu-me serviço de Deus e de V.A. mandá-los buscar em um navio, e trazê-los a São Vicente; parecendo-me que as mulheres vieram tão enfadadas dos trabalhos que passaram, que casarão aí com quem lhes der de comer, e os homens, que farão cada um a sua roça. E parti com eles, dessa pobreza minha que levava; e não foi tão pouco que não fosse mais do que eu tinha de meu de trinta e cinco anos.

11 - Pelo Rio da Prata, arriba 300 léguas da barra, ao Norte e ao Nordeste, está uma povoação grande de castelhanos, da gente que ali levou Dom Pedro de Mendonça, a qual está em 25 graus e um quarto, e São Vicente está em 23 e 3 quartos. Foi-se agora descobrindo, pouco a pouco, que esta povoação que se chama a cidade d'Assunção, está muito perto de São Vicente, e não devem de passar de cem léguas, porque, pela altura, se vê logo claramente. Parece-nos, a todos, que esta povoação está na demarcação de V.A., e se Castela isto negar, mal pode provar que é Maluco seu; e se estas palavras parecem a V.A. de mau esperiquo e pior cosmógrafo, terá V.A. muita razão, que eu não sei nada disto, senão desejar que todo o mundo fosse de V.A. e de vossos herdeiros. Achei que os de São Vicente se comunicavam muito com os Castelhanos, e tanto que na Alfândega de V.A. rendeu este ano passado cem cruzados de direitos, de cousas que os castelhanos trazem a vender. E por ser com esta gente que parece que por castelhanos não se pode V.A. desapegar deles, em nenhuma parte, ordenei, com grandes penas, que este caminho se evitasse, até o fazer saber a V.A., e pôr nisto grandes guardas, e foi a causa por onde folguei de fazer as povoações que tenho dito no campo de São Vicente. Da maneira que me parece que o caminho estará vedado; acuda V.A. com muita brevidade a mandar o que nisto há por seu serviço; e, em todo o modo, responda V.A. a este capítulo, que em cousas tão novas não me sei determinar; porque a tenção dos Castelhanos era irem-se por terra para a sua povoação.

12 - Os Irmãos da Companhia de Jesus fazem nesta terra muito serviço a Deus, por muitas vias, como por vezes tenho escrito a V.A. Tem eles grande fervor de irem pela terra a dentro a fazer casas no sertão, entre o gentio, e lho defendi de maneira, e com as palavras com que se 
devem defender as tais obras, dizendo-lhes que assim, com se for V.A. alargando, se vão eles também. E que se quisessem entrar pela terra a dentro, que o façam dois ou três, com os seus línguas, a pregarem ao gentio mas, irem a fazer casa entre eles, me não parece bem, por agora, senão em nossa companhia.

13 - Sinto isto muito e de maneira que o tomem como martírio que lhes eu desse. V.A. acuda logo a isto logo, porque não queria eu ter com homens tão virtuosos e tanto meus amigos, diferenças de pareceres, porque tenho sempre o meu por pior, e, se não para toda esta costa, contra esta opinião, não ousava eu de lho impedir.

14 - De São Vicente até o Rio da Prata estavam algumas armas de Castela. Em algumas partes mandei-as tirar e deitar no mar, e por as de V.A.

15 - Correndo esta costa, achei entre o gentio, nova mais quente d'ouro, do que me a mim parece, nem parecera, até que o veja, pelo muito que o desejo; todavia ordenei doze homens e um clérigo, Irmão da Companhia de Jesus, como eles, e estão para entrar pela terra firme. Pela via de Porto Seguro e por Pernambuco são já entrados outros. Quererá nosso Senhor, que pois V.A. parte também com ele do que tem, que trarão estes homens nova de algum grande tesouro.

Da Cidade do Salvador, ao primeiro de junho de 1553.

\section{Tomé de Sousa}

Sobrescrito: A El Rei nosso Senhor.

(Arquivo da Torre do Tombo, Gav. 18, m. 8, n. 8)

História da Colonização Portuguesa do Brasil, T. III, p. 364 a 366. 